\title{
Actuele ontwikkelingen rondom XBRL in de wereld
}

Dave van den Ende en Cees de Boer

SAMENVATTING Steeds vaker wordt bedrijven gevraagd of verplicht om hun financiële bedrijfsresultaten digitaal te rapporteren. In veel gevallen wordt daarbij gekozen voor de rapportagestandaard XBRL (eXtensible Business Reporting Language). Het Europees Parlement heeft in juni van dit jaar besloten dat per 2020 alle beursgenoteerde ondernemingen in Europa hun jaarverslag op een digitale wijze moeten gaan rapporteren. In Nederland wordt digitaal rapporteren met XBRL al vanaf 2013 verplicht voor zowel kleine als grote ondernemingen. In dit artikel wordt ingegaan op de betekenis van deze verplichtstellingen en de impact hiervan op het rapportageproces van ondernemingen.

RELEVANTIE VOOR DE PRAKTIJK Door een goede aansluiting van de interne rapportageprocessen op de toenemende eisen om digitaal te rapporteren op basis van de XBRL-standaard, kunnen ondernemingen de administratieve lasten hiervan beperken. Daarbij is het mogelijk zelfs voordeel te halen door een efficiënter rapportageproces en een hogere kwaliteit van de data te bieden aan investeerders en andere stakeholders.

\section{Inleiding}

In Nederland is de overheid in samenwerking met het bedrijfsleven al enige tijd bezig om papieren rapportagestromen te vervangen door digitale rapportagestromen. Dit gebeurt onder de vlag van het Standard Business Reporting (SBR-)programma ${ }^{1}$. Het SBR-programma heeft tot doel om zowel de definities van de uit te wisselen gegevens te standaardiseren, als het aanleverproces van rapportages van ondernemingen aan ontvangende partijen, zoals Belastingdienst, CBS en Kamer van Koophandel te standaardiseren. Uit de wereldwijd groeiende adoptie van XBRL door overheden en toezichthouders (zie figuur 2) mag afgeleid worden dat ontvangende partijen voordeel behalen uit de digitale verwerking van bedrijfsinformatie. Maar wat betekenen deze ontwikkelingen voor ondernemingen, de aanleverende partijen? En wat is de internationale positie van Nederland op dit terrein? In de volgende paragrafen wordt de context geschetst die aanleiding is voor digitalisering van rapportagestromen. Daarna wordt een overzicht gegeven van recente ontwik- kelingen in Nederland en in de wereld op het terrein van digitaal rapporteren waarbij XBRL als rapportagestandaard wordt gehanteerd. Vervolgens wordt ingegaan op de effecten van digitaal rapporteren voor ondernemingen en de impact op hun rapportageprocessen.

\section{Digitalisering van rapportagestromen}

Ondanks de steeds verdergaande digitalisering van onze samenleving lijkt het papieren jaarverslag nog vaak de basis te zijn voor de analyse van de financiële verantwoording van bedrijven. Tegelijkertijd zijn er steeds meer stakeholders die digitale informatie wensen voor hun analyses. Volgens de US Securities Exchange Commission (US SEC), de Amerikaanse beurstoezichthouder, bevat echter $28 \%$ van de data die door analisten wordt gebruikt fouten (Cox, 2006). Uit onderzoek van Boritz en No (2013) blijkt dat informatie van US-genoteerde bedrijven in systemen van data aggregators als Compustat, Google Finance en Yahoo Finance een gemiddeld foutpercentage heeft van $4,8 \%$. Hoewel dit een klein percentage lijkt, is gemiddeld $56,3 \%$ hiervan materieel. Bovendien is de mate van detail erg beperkt, zodat het moeilijk is om een volledig beeld te krijgen van de onderneming. In figuur 1 wordt getoond dat meer dan $50 \%$ van de feiten in de jaarrekening niet digitaal beschikbaar is in de systemen van de data aggregators vergeleken met de gegevens die bedrijven publiceren aan de US SEC en die beschikbaar zijn via de EDGAR-website ${ }^{2}$ van de US SEC.

\section{Figuur 1 Resultatenvergelijking met digitale US SEC data (bron: Boritz \& No, 2013)}

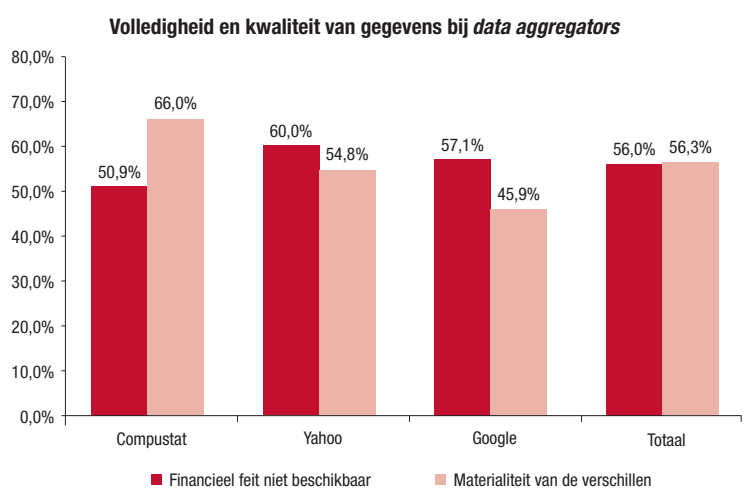


Het onderzoek van Boritz en No (2013) draagt bij aan de bewustwording dat verslaggeving verder gaat dan een mooie lay-out van het traditionele 'boekje'; alle partijen in de rapportageketen zullen zich moeten verdiepen in de wijze waarop digitale bedrijfsinformatie wordt gebruikt en hoe het digitale rapportageproces moet worden ingericht om effectief te communiceren in de digitale wereld. Gebruikers zullen de digitale informatie opnemen in hun eigen analysesystemen en daarbij niet altijd de volledige context en samenhang van de informatie behouden. Dit is een belangrijke bron van fouten. Als ondernemingen zich hiervan bewust zijn en de eigen informatie van de juiste tag voorzien, wordt een betere beheersing mogelijk van de informatie die door stakeholders wordt (her)gebruikt. Deze tags geven de context en samenhang aan van de gerapporteerde informatie en vereenvoudigen daardoor de interpretatie van de informatie.

De XBRL-standaard vormt een belangrijke schakel in het vastleggen en documenteren van de context en samenhang van gepubliceerde informatie; een XBRLtaxonomie voorziet in de mogelijkheid om de semantische betekenis van informatie en de onderlinge samenhang tussen informatie-elementen te beschrijven. Bovendien stelt het gebruikers van een XBRL-taxonomie in staat om deze rechtstreeks te koppelen aan hun bronsystemen zodat een rapportage rechtstreeks en volledig geautomatiseerd kan worden gegenereerd vanuit het bronsysteem. Gebruikers van de informatie kunnen dezelfde XBRL-taxonomie hanteren als referentie voor het interpreteren van de informatie.

\section{Internationale ontwikkelingen in digitaal rapporteren}

In navolging van de US SEC heeft het Europese Parlement in juni 2013 besloten dat alle beursgenoteerde ondernemingen in Europa per 1 januari 2020 digitaal moeten gaan rapporteren (European Commission, 2013a). Om de toegankelijkheid, analyse en vergelijkbaarheid te bevorderen, moeten de bedrijven gebruikmaken van een eenduidige digitale standaard. In de US en Europa is dat XBRL. Maar ook toezichthouders in Azië en het Midden-Oosten adopteren de XBRL-standaard om informatie van ondernemingen digitaal beschikbaar te stellen aan de markt ${ }^{3}$.

\section{Figuur 2 Verplichte/vrijwillige invoering van XBRL}

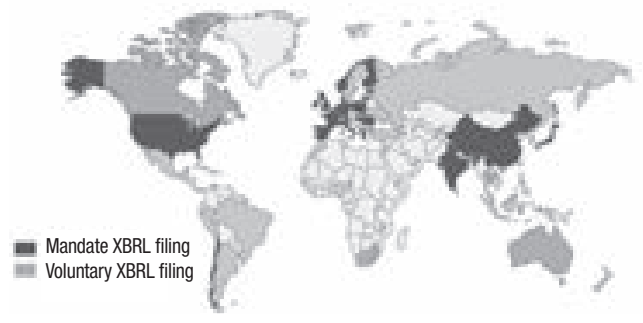

Bovendien heeft het Europees Parlement de afgelopen maanden grote stappen gezet in het vergroten van de transparantie in het bank- en verzekeringswezen. $Z_{0}$ zullen de centrale banken binnen Europa vanaf 1 januari 2014 in XBRL moeten gaan rapporteren aan de European Banking Authority (EBA) ${ }^{4}$. De European Insurance and Occupational Pensions Authority (EIOPA) heeft eveneens aangekondigd voor Solvency II-rapportages de XBRL-standaard te adopteren. Veel centrale banken binnen Europa vertalen deze rapportagevereisten naar een verplichting voor lokale banken om in XBRL te rapporteren.

\section{Rapportage niet-financiële informatie}

Naast de rapportagevereisten voor financiële informatie van ondernemingen, krijgt ook de rapportage van niet-financiële informatie steeds meer aandacht. De Europese Commissie (2013b) heeft in april 2013 een wijziging in de jaarrekeningenwetgeving voorgesteld om ervoor te zorgen dat ondernemingen met meer dan 500 werknemers transparanter worden over hun sociaal en milieubeleid. De betrokken ondernemingen zullen informatie moeten bekendmaken over beleidskeuzes, risico's en resultaten van milieu-, sociale en personeelsaspecten, respect voor mensenrechten, diversiteit in de raad van bestuur en strijd tegen corruptie en omkoping. Volgens het voorstel moeten de ondernemingen in hun jaarverslagen relevante en feitelijke informatie verstrekken over milieu- en sociale aangelegenheden. ${ }^{5}$ Het is nog niet duidelijk of deze informatie ook onder de transparantierichtlijn valt en digitaal moet worden gerapporteerd. Om ondernemingen in staat te stellen om digitaal over hun sociaal en milieubeleid te publiceren, hebben CDP (Carbon Disclosure Project) en GRI (Global Reporting Initiative) ${ }^{6}$ de XBRL-standaard reeds geadopteerd en taxonomieën gepubliceerd. IIRC (International Integrated Reporting Council) heeft onlangs in haar marktconsultatie eveneens aandacht gevraagd voor de mogelijkheden van XBRL voor de digitale ontsluiting van integrated reports ${ }^{7}$.

Ook het midden- en kleinbedrijf krijgt steeds vaker te maken met digitale rapportagevereisten. Binnen Europa hebben landen als België, Denemarken, Duitsland, Engeland, Ierland en Spanje al enige tijd het rapporteren in XBRL verplicht gesteld voor onder meer het deponeren van financiële jaarverslagen en het indienen van belastingaangiften. Nederland is dit jaar gestart met het verplicht stellen van XBRL voor de aangifte vennootschapsbelasting en de IB-winst. De komende jaren zullen ook andere rapportages in XBRL verplicht worden.

\section{Voordelen voor gebruikers}

De toename van digitale data lijkt vooral voordelen te bieden voor de gebruikers van de informatie (zie bijvoor- 
beeld FFIEC, 2006). Financiële analisten en investeerders krijgen betere toegang tot informatie en zijn beter in staat om analyses op de data te doen. Data-analisten kunnen processen efficiënter inrichten en het aantal overtypfouten verminderen. Bedrijven profiteren ook, omdat de uitwisseling van informatie tussen organisaties wordt vereenvoudigd als ze gebruikmaken van dezelfde standaard.

Een voorbeeld van de wijze waarop gebruikers over de informatie kunnen beschikken, is het Accounting Quality Model (Lewis, 2012) dat onlangs door de US SEC werd aangekondigd. Dit model is ontworpen om een reeks kwantitatieve analyses te kunnen uitvoeren op de gerapporteerde XBRL-datasets die de US SEC gebruikt om te beoordelen of zich in de financiële rapportages van bedrijven relevante afwijkingen voordoen. In het verleden deed de US SEC vooral een beroep op de markt om boekhoudkundige problemen te signaleren. Vandaag de dag wil de US SEC een meer proactieve rol spelen door het gebruik van risicomodellen. Hiermee worden de rapportages van de ondernemingen geanalyseerd om uitschieters en onvolkomenheden te identificeren in de rapportage van hun resultaten. In deze analyse wordt ook gekeken naar de tekstuele toelichtingen in de financiële verslagen over de resultaten van het bedrijf en de vooruitzichten voor de toekomst.

\section{Digitaal rapporteren in Nederland}

In Nederland wordt binnen het Standard Business Reporting-programma al enige jaren gewerkt aan de standaardisatie van rapportagestromen naar Belastingdienst, CBS en Kamers van Koophandel. Deze standaardisatie ligt op twee niveaus. Enerzijds zijn de te rapporteren gegevens gestandaardiseerd en vastgelegd in de Nederlandse (XBRL) Taxonomie. Een grote stap om te voorkomen dat elke uitvrager van informatie een eigen taxonomie bepaalt. Anderzijds is het proces van de digitale aanlevering en verwerking van de rapportages gestandaardiseerd en kunnen bedrijven hun elektronische berichten aanbieden aan één elektronische postbus, genaamd Digipoort. In aansluiting hierop hebben ook de drie grote Nederlandse banken (ABNAMRO, ING en Rabobank) een samenwerking opgezet om een gestandaardiseerde XBRL-rapportage te ontwikkelen voor de kredietrapportage van bedrijven.

Hoewel zowel private als publieke partijen dit programma al enige jaren actief ondersteunen, was het aantal berichten dat langs deze weg werd uitgewisseld laag. Daarom zijn overheid en markt overeengekomen om de uitwisseling van deze berichten op gang te brengen door SBR stapsgewijs verplicht te stellen (zie figuur 3). Met de verplichte indiening van de aangifte IB/VPB is hiermee op 1 januari 2013 een start gemaakt. Per 1 januari 2014 zijn kleine ondernemingen verplicht om de jaarrekening in XBRL te rapporteren. Deze verplichting geldt per 1 januari 2015 voor grote (controleplichtige) ondernemingen. Dit betekent dat vanaf deze data XBRL het enige digitale formaat is dat door de Kamer van Koophandel zal worden geaccepteerd voor de deponering van jaarrekeningen. Om de deponering van papieren jaarrekeningen af te schaffen, is een wetswijziging nodig welke op het moment van dit schrijven in voorbereiding is.

\section{Figuur 3 Invoering van SBR-rapportages in Nederland}

\begin{tabular}{|c|c|c|}
\hline Ontvangers & Rapportage & Verplicht* \\
\hline 60 & $\begin{array}{l}\text { Publicatiestukken kleine on- } \\
\text { dernemingen } \\
\text { Publicatiestukken middel- } \\
\text { groot } \\
\text { Publicatiestukken groot }\end{array}$ & $\begin{array}{l}2014 \\
2015 \\
2015 \\
\end{array}$ \\
\hline Belastingdiense & $\begin{array}{l}\text { Inkomstenbelasting (IB) } \\
\text { Vennootschapsbelasting } \\
\text { (VPB) } \\
\text { Verkorte winstaangifte IB, } \\
\text { VPB (FJR) } \\
\text { Omzetbelasting } \\
\text { Intracommunautaire Presta- } \\
\text { ties (ICP) }\end{array}$ & $\begin{array}{l}2013 \\
2013 \\
2013 \\
2014 \\
2014\end{array}$ \\
\hline E[n] & $\begin{array}{l}\text { Productie-/jaarstatistiek } \\
\text { Enquête investeringen en } \\
\text { lease } \\
\text { Korte termijn-/omzetstatistie- } \\
\text { ken }\end{array}$ & $\begin{array}{c}\text { Nog geen } \\
\text { verplichting }\end{array}$ \\
\hline 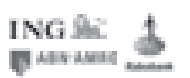 & Kredietrapportage & $\begin{array}{l}\text { Nog geen } \\
\text { verplichting }\end{array}$ \\
\hline
\end{tabular}

Het effect van de verplichtstelling is significant. Al in het eerste kwartaal ontving de Belastingdienst ruim 1,5 miljoen berichten.

\section{Positie Nederland binnen Europa}

Binnen Europa, maar zeker ook internationaal gezien, is Nederland een voorloper bij het toepassen van XBRL in de digitalisering van rapportageprocessen. Hoewel de berichtenstromen nu pas echt op gang komen, onderscheidt de Nederlandse aanpak zich nog steeds fundamenteel van andere landen. Vanaf het begin is in Nederland de keuze gemaakt voor een volledige digitalisering van het bericht. Dit betekent dat alle informatie die wordt uitgewisseld voorzien is van een unieke tag en daardoor automatisch kan worden verwerkt. Sommige landen, zoals de UK en Ierland, hebben gekozen voor een snelle introductie van digitaal rapporteren. Daarbij hebben zij er voor gekozen om slechts delen van het bericht te voorzien van een unieke tag door de toepassing van iXBRL. Ook zijn er landen waar de ontvangende instantie het XBRL-bericht pas aanmaakt nadat de ondernemer de data in een ander formaat heeft aangeleverd of handmatig heeft ingevoerd in een internetportaal. 
Ook heeft Nederland een koploperspositie bij de kwaliteitsborging van XBRL-rapportages. Zo ontwikkelt de NBA (Nederlandse Beroepsorganisatie Accountants) een XBRL-taxonomie voor de accountantsverklaring. Deze is noodzakelijk om controleplichtige bedrijven in de gelegenheid te stellen een volledig digitale jaarrekening in XBRL te publiceren, inclusief de digitale accountantsverklaring die hoort bij deze digitale jaarrekening.

\section{Effect van digitaal rapporteren op ondernemingen}

Analisten en andere stakeholders van de organisatie gebruiken veelal digitale bronnen om data van ondernemingen in hun analysemodellen te betrekken. De jaarrekening is dus slechts het begin van een nieuwe keten. Als analisten de keuze wordt geboden, kiest $66 \%$ voor XBRL-data als bron en 34\% voor spreadsheetdata (Janvrin, Pinsker \& Mascha, 2011). Geen van de analisten zou voor pdf-documenten kiezen als databron. Deelnemers aan dit onderzoek noemden de bekendheid met de technologie het belangrijkste argument om voor spreadsheetdata te blijven kiezen. Als belangrijkste argument om voor XBRL-data te kiezen werd de tijdsbesparing genoemd om een financiële analyse uit te voeren op basis van informatie die bedrijven publiceren op hun investor relations websites en de website van de US SEC.

Als een onderneming de jaarrekening in XBRL rapporteert, biedt dit voor de onderneming belangrijke voordelen:

- Doordat een XBRL-taxonomie de unieke betekenis van gegevens bevat, is er minder onduidelijkheid over definities en de semantische betekenis van begrippen (Melse \& Weltevreden, 2013).

- Stakeholders en analisten krijgen toegang tot informatie van betere kwaliteit, omdat overtypen van de data niet meer nodig is (Wang \& Gao, 2012).

- Aan de hand van de taxonomie kunnen gebruikers de informatie direct terugvinden en is het niet nodig om het gehele rapport te doorzoeken. Hierdoor maken gebruikers van de informatie ook minder interpretatiefouten (Henderson, 2012).

- XBRL-rapportages bevatten meer gedetailleerde informatie, waardoor de kosten van hergebruik dalen en nieuwe mogelijkheden ontstaan voor benchmarking en controle (Harris \& Morsfield, 2011).

- Door lagere kosten van de informatieverwerking kunnen analisten meer ondernemingen betrekken in hun analysemodellen, waardoor ondernemingen mogelijk een betere toegang krijgen tot de kapitaalmarkt (Anoniem, 2013)

\section{"XBRL Inside"}

Dat deze voordelen niet alleen van toepassing zijn op externe rapportages van een onderneming, maar ook tot grote kostenvoordelen kunnen leiden in de interne rapportageprocessen, is minder bekend. In feite is het nu gebruikte externe rapportagemodel - veel verschillende ondernemingen rapporteren met dezelfde standaard aan één centrale organisatie (zoals de US SEC of de Kamer van Koophandel) - heel vergelijkbaar met de rapportageketen binnen een grote organisatie met veel dochterondernemingen en een holding. Daar worden ook al taxonomieën gebruikt, zoals bijvoorbeeld de standard chart of accounts. Door het gebruik van XBRL kan de interne uitwisseling van gegevens gestandaardiseerd en geautomatiseerd worden, waardoor de efficiëntie en effectiviteit van het interne rapportageproces kan worden verbeterd. Vooral als er sprake is van een groot aantal rapporterende entiteiten (bijvoorbeeld dochterondernemingen) die maandelijks rapporteren aan de holding, zijn de hiervoor genoemde voordelen voor de ontvangende partijen ook hier van toepassing.

Maar er zijn meer voordelen. Denk aan directe koppeling van de interne XBRL-rapportage aan het grootboek; softwareapplicaties maken het nu al mogelijk om rechtstreeks vanuit het grootboek op geautomatiseerde wijze XBRL-rapportages te genereren.

Ofschoon er momenteel slechts enkele organisaties zijn die XBRL intern toepassen (zie Haseqawa, Sakata, Sambuichi, \& Hannon, 2004; Rose, 2012), neemt door de verplichtstellingen de kennis en ervaring met XBRL in veel organisaties toe en is het denkbaar dat daar waar XBRL dé standaard is voor externe rapportages, organisaties de XBRL-standaard zullen meenemen in hun overweging om interne rapportageprocessen te stroomlijnen. Zeker in gevallen waar rapportageprocessen organisatieoverstijgend zijn en meerdere (externe) partijen onderdeel zijn van de rapportageketen, zou XBRL een goede bijdrage kunnen leveren aan het bepalen van de uit te wisselen gegevens (door het opstellen van een XBRL-taxonomie) en de automatisering van het rapportageproces.

\section{Conclusies}

De hiervoor beschreven ontwikkelingen maken duidelijk dat de digitalisering van rapportageprocessen een onomkeerbaar proces is. Ofschoon veel bedrijven de nieuwe eisen in eerste instantie ervaren als een toename van de administratieve lasten, zijn ook zij gebaat bij een efficiënter en effectiever rapportageproces. Dat vraagt om innovatie in het huidige denken en doen. Digitaal rapporteren vraagt om ketendenken. Het feit dat de overheden en toezichthouders XBRL verplicht stellen, is louter een kwestie van het in gang zetten van dit proces. Verplichting schept duidelijkheid voor alle partijen in de rapportageketen, waardoor alle partijen in de keten bereid zijn om te investeren in het efficiënter maken van het rapportageproces. 
Om digitalisering van rapportageketens te realiseren, zijn afstemming en overleg over de semantische betekenis van de informatie noodzakelijke vereisten. De ervaring die we in Nederland hiermee de afgelopen jaren hebben opgedaan binnen het SBR-programma, nodigt uit om de toepassing hiervan te verbreden naar andere rapportageketens, zoals de financiële verantwoording binnen de onderwijs- en zorgketen of de uitwisseling van gegevens voor het gebruik van branchevergelijkingen.
Drs. D.G. van den Ende is director bij Deloitte Nederland en als bestuurslid van XBRL Nederland, lid van de XBRL Advisory Committee van IASB en vice-voorzitter van EU Adoption Committee van XBRL Europe nauw betrokken bij de XBRL-ontwikkelingen binnen Europa. C.J.G.M. de Boer RA is CFO en COO van Deloitte Nederland en lid van de Global Board of Directors van Deloitte. $\mathrm{Hij}$ is tevens lid van de Board van XBRL International.

\section{Noten}

1 Zie ook www.sbr-nl.nl.

2. http://www.sec.gov/edgar.shtml

3. Zie overzicht XBRL-projecten op www.Xbrl. org/knowledge_centre/projects/map.
Zie http://eba.europa.eul-/update-on-thetechnical-standards-on-supervisory-reporting-requirements.

5 _ Zie http://europa.eu/rapid/press-release_IP- 13-330_nl.htm.

Zie www.globalreporting.org.

Zie http://www.theilrc.org/consultationdraft2013/.

\section{Literatuur}

- Anoniem (2013). Analyst community perspectives on XBRL . Geraadpleegd op http:// xbrl.us/News/Pages/20130523.aspx.

- Boritz, J.E., \& No, W.G. (2013). The quality of interactive data: XBRL versus Compustat, Yahoo Finance, and Google Finance. Geraadpleegd op http://dx.doi.org/10.2139/ ssin.2253638

- Cox, C. (2006). Opening remarks to the practicing law institute's sec speaks series. Geraadpleegd op http://www.sec.gov/news/ speech/spch030306cc.htm.

- European Commission (2013a). Revised directive on transparency requirements for listed companies (transparency directive): Frequently asked questions. Geraadpleegd op http://europa.eu/rapid/press-release_MEMO13-544_en.htm.

- European Commission (2013b). Commission moves to enhance business transparency on social and environmental matters (IP/13/330). Geraadpleegd op http://europa.eu/rapid/ press-release_P-13-330_en.htm.

- European Commission (2011). Proposal for a directive of the European Parliament and of the Council amending directive 2004/109/EC on the harmonisation of transparency requirements in relation to information about issuers whose securities are admitted to trading on a regulated market and Commission (Directive 2007/14/EC). Geraadpleegd http://ec.europa. eu/internal_market/securities/transparency/.

- Federal Financial Institution Examination Council (FFIEC) (2006). Improved business process through XBRL: A use case for business reporting. Geraadpleegd op http://xbrl. org/us/us/FFIEC\%2OWhite\%20Paper\%20 31.Jan06.pdf.

- Harris, T.S., \& Morsfield, S.G. (2011). An evaluation of the current state and future of XBRL and interactive data for investors and analysts. Geraadpleegd op http://www4.gsb.columbia.edu/filemgr?\&file_id=7313146.

- Haseqawa, M., Sakata, T., Sambuichi, N., \& Hannon, N. (2004). Breathing new life into old systems with XBRL-GL. Strategic Finance, 85(9), 46-51.

- Henderson, C. D. (2012). Standardizing the presentation of financial data: Does XBRL's taxonomy affect the investment performance of nonprofessional investors? Geraadpleegd op http://digitalcommons. utep.edu/disserta-
tions/AAl3552245.

- Janvrin, D.J., Pinsker, R.E., \& Mascha, M. (2011). XBRL, Excel or PDF? The effects of technology choice on the analysis of financial information (CAAA Annual Conference 2011). Geraadpleegd op http://dx.doi.org/10.2139/ ssrn.1740249.

- Lewis, C.M. (2012). Risk modeling at the SEC: The accounting quality model. Geraadpleegd op http://www.sec.gov/news/speech/2012/ spch121312cml.htm.

- Melse, E., \& Weltevreden, J.W.J. (2013). SBR in bedrijf. Een onderzoek naar de mogelijkheden van Standard Business Reporting voor MKB-bedrijven in Nederland. Geraadpleegd op http://www.carem.hva.nl/wp-content/uploads/2013/03/SBR-in-Bedrijf.pdf.

- Rose, S. (2012). Automating reporting worth it says Suncorp. Geraadpleegd op http://afr. com/f/free/markets/capital/cfo/compliance_ as_you_go_5EOweXWlaGz68V2usv6hUK.

- Wang Z., \& Gao, S. (2012). Are XBRL-based financial reports better than non-XBRL reports? A quality assessment. International Journal of Economics and Management Sciences, 6, 513-518. 